\title{
Unrecognised nocturnal hypoglycaemia masquerading as senile dementia
}

\author{
R. RAMASAMY* \\ M.A., M.R.C.P.
}

Friarage Hospital, Northallerton, North Yorkshire

\begin{abstract}
Summary
A 70-year-old woman with insulin dependent diabetes mellitus presented with symptoms suggestive of senile dementia. Outpatient assessment failed to reveal poor diabetic control with frequent nocturnal hypoglycaemia. Eventual appreciation of the poor control resulted in several failed attempts at improving therapy with various subcutaneous insulin regimes. Intramuscular and intravenous routes produced acceptable blood glucose levels with striking reversal of the patient's symptoms. The possible causes of nocturnal hypoglycaemia in this patient are discussed.
\end{abstract}

KEY WORDS: senile dementia, nocturnal hypoglycaemia.

\section{Introduction}

Unstable diabetes mellitus with nocturnal hypoglycaemic episodes may be difficult to detect, particularly in the elderly. Symptoms can be non-specific and may resemble those of senile dementia. Improved control can result in the reversal of symptoms. Though insulin overtreatment is the commonest cause of nocturnal hypoglycaemia, there are alternative mechanisms.

\section{Case report}

A 57-year-old woman was found to have diabetes mellitus in 1968 and became insulin-dependent in 1970, requiring 28 units of Lente insulin daily. Control was difficult even at the early stages, and on one occasion in 1974 she was admitted with transient hemiplegia due to hypoglycaemia. In 1977, a diagnosis of hypothyroidism was made on the basis of an elevated serum thyroid stimulating hormone (TSH) level. Despite adequate thyroxine replacement, she became increasingly disabled by considerable lack of energy with a tendency to fall asleep during the day. Her concentration was poor and she was unable to read the novels she had previously enjoyed. Her

*Present address: Derby City Hospital, Derby DE3 3NE. mood also fluctuated in that she would become inexplicably weepy at times. Her husband noticed frequent confusional states and a tendency to forget recent events and dates. On several occasions she had set out shopping, only to return home having forgotten the purpose of her journey. There were no episodes of loss of consciousness.

Her urinalysis charts and outpatient random blood glucose levels appeared to reflect apparent satisfactory diabetic control, though the range of blood glucose levels were wide $(4 \cdot 2-20 \mathrm{mmol} /$ litre). In 1978 , she was briefly admitted and therapy changed to a twice daily combination of soluble and isophane insulin. Daytime inpatient blood glucose levels ranged from 9.9-20.0 mmol/litre. Her symptoms persisted. Investigations of her apparent senile dementia included a computerised tomography brain scan in 1978 which showed moderate cortical atrophy with consequent enlargement of the lateral ventricles. Between 1979 and 1981, she had frequent visits to the outpatient department with increasingly incapacitating symptoms. On one such visit in 1981, her blood glucose level was $1.7 \mathrm{mmol} /$ litre and her only complaint was one of somnolence. She was admitted in August 1981 for reassessment.

At admission she was on thyroxine $150 \mu \mathrm{g}$ daily; soluble insulin 24 units and isophane insulin 8 units with breakfast, isophane insulin 10 units in the evening. Examination revealed a lethargic patient, with a blood pressure of $140 / 80 \mathrm{mmHg}$ lying and standing but otherwise normal and with no evidence of significant diabetic neuropathy or retinopathy.

Investigations showed blood haemoglobin $\mathrm{A}_{\mathrm{lc}}$ level of $11.8 \%$ (normal range 5-10\%). Serum cortisol levels (nmol/litre) were; 9 a.m. 1332, 12 midnight 246. The blood glucose $7 \mathrm{hr}$ before the 9 a.m. cortisol level was only $2 \cdot 2 \mathrm{mmol} / \mathrm{litre}$. Serum insulin binding capacity of $2.7 \mathrm{ng} /$ litre (normal up to $3 \mathrm{ng} /$ litre). C-peptide levels were undetectable in 3 separate specimens taken during a $36-\mathrm{hr}$ period when corresponding blood glucose levels were $13.9,11.6$ and $2.2 \mathrm{mmol} /$ litre. 
Attempts at control with various subcutaneous insulin regimes were unsuccessful. The major problems were with nocturnal hypoglycaemia in the absence of specific symptoms. There was a tendency towards ketoacidosis in the daytime with a typical 24hr blood glucose profile ranging $2 \mathrm{mmol} /$ litre to 28 mmol/litre.

In December 1981, control was attempted with continuous subcutaneous purified soluble insulin administered by a lightweight battery-operated infusion pump. Despite reducing the infusion rate to $1-2$ units/hr between 7 a.m. to 7 p.m. with 4 unit booster doses at breakfast and lunch, frequent blood glucose readings below $2.5 \mathrm{mmol} /$ litre persisted at 2 a.m. A notable feature during this period was the rapidity of smooth control with intravenous insulin infusions and, therefore, long-term intramuscular infusions were commenced in February 1982 using a method suggested by Pickup et al. (1981). Her blood glucose levels ranged $3 \cdot 7-14.7 \mathrm{mmol} /$ litre over a $24-\mathrm{hr}$ period using 2 units/hr infusions from 7 a.m. to 7 p.m. with $\frac{1}{2}$ unit/hr from 7 p.m. to 7 a.m.

Throughout this difficult period, a striking feature was the obvious improvement in well-being appreciated by the patient, her relatives and ward staff whenever periods of satisfactory control were achieved. During such periods, she was subjected to psychometric testing and normal scores were achieved in tests using Raven's progressive matrices and the Mill Hill vocabulary test.

Regrettably, following a satisfactory period on intramuscular insulin infusion, the patient developed an episode of diabetic ketoacidosis due to blockage of the intramuscular cannula, from which she died.

\section{Discussion}

Chronic nocturnal hypoglycaemia is an important and not uncommon condition in the insulin-dependent diabetic, but it is difficult to diagnose (Gale and Tattersall, 1979; Dornan et al., 1981). This patient's symptoms were typically non-specific and routine outpatient assessment failed to detect underlying poor control, leading to a mistaken diagnosis of senile dementia.

As in the case described, high early morning cortisol or surprisingly 'normal' haemoglobin $\mathbf{A}_{\mathrm{lc}}$ levels (Dornan et al., 1981) may aid diagnosis. However, any patient with such symptoms must have a full 24-hr blood glucose profile even if diabetic control appears satisfactory by other criteria. Studies on the effects of neuroglycopaenia suggest that major metabolic and structural changes result in the brain (Agardh et al., 1980). The findings of the computerised brain scan on this patient may have been related to her repeated hypoglycaemia.
Nocturnal hypoglycaemia is more common caused by insulin overtreatment in an attempt $\mathscr{\infty}$ achieve morning normoglycaemia. Alternatively, B⿺den et al. (1981) suggest that the reduced release $\overrightarrow{\mathrm{d} f}$ counter-regulatory hormones may cause undue senstivity to insulin-induced hypoglycaemia. Attentięn has also been drawn to the possibility of hypoglyca mia being caused by the release of antibody-bound insulin (Harwood, 1960), but the insulin binding capacity in this patient was normal. C-peptide levers were normal at the time of hypoglycaemia, excludies the possibility of inappropriate intrinsic insulin production (Bonser and Garcia-Webb, 1981). R $\overrightarrow{\mathrm{K}}$ cently, Taylor et al. (1982) pointed out that insuliog receptor antibodies may also cause hypoglycaem. None of these mechanisms, however, explain why, 疍 this patient, comparable doses of intramusculer insulin abolished those persistent hypoglycaemig attacks occuring with subcutaneous insulin infusion often several hours after the infusion was stopped or

The wild swings from hyperglycaemia to hypoglycaemia in this patient are typical of 'brittle' diabetes. Subcutaneous insulin infusions achieve excelle $\vec{y}$ control in most diabetics (Pickup et al., 1979), but ngt in brittle diabetics because there appear to problems in insulin absorption at the subcutaneo site (Pickup et al., 1981). Similarly, in this patien 6 the route of insulin administration was critical. ger attacks of hypoglycaemia were probably due $\mathbb{Q}$ erratic subcutaneous insulin absorption. The ifesence of subcutaneous proteases may cause unstabde diabetes mellitus in some patients, but unlike the patient they require large doses of insulin (Freide berg et al., 1981). Variations in cutaneous bloof supply were more probably responsible for errape insulin absorption. Nocturnal hypoglycaemia due $\overrightarrow{\mathbb{O}}$ erratic insulin absorption is more difficult to recognise because the dose of insulin required need not large. While intramuscular insulin infusions circurnvent these problems, they have their own major practical difficulties.

\section{Acknowledgments}

I am grateful to Dr J. Hampson and Dr E. W. Barnes for thar advice and permission to publish this report on their case, and to Miss J. Husband for secretarial help.

\section{References}

Agardh, C.D., Kalimo, H., Olsson, Y. \& Siesjo, B.K. (19809 Hypoglycaemic brain injury I \& II. Acta Neuropathologe (Berlin), 50, 31.

Boden, G., ReichaRd, G.A., HoeldtKe, R.D., Rezvani, I., OWEิ O.E. (1981) Severe insulin induced hypoglycaemia associated wh deficiency in the release of counterregulatory hormones. NE⿱ England Journal of Medicine, 305, 1200. 
Bonser, A.M. \& GaRCIA-WebB, P. (1981) C-Peptide measurement and its clinical usefulness; a review. Annals of Clinical Biochemistry, 18, 200.

Dornan, T.I., Pekar, C.O., Mayon-White, V.A., Hockaday, T.D., KNIGHT, A.H., MOORE, R.A., BRON, A.J. \& TURNER, R.C. (1981) Unsuspected hypoglycaemia, haemoglobin $\mathrm{Al}$ and diabetic control. Quarterly Journal of Medicine, 197, 31.

Freidenberg, G.R., White, N., CaTaland, S., O'Dorisio, T.M., Sotas, J.F. \& SANTIAGO, N. (1981) Diabetes responsive to intravenous but not subcutaneous insulin; effectiveness of aprotinin. New England Journal of Medicine, 305, 363.

GALE, E.A.M. \& TATTERSALL, R.B. (1979) Unrecognised nocturnal hypoglycaemia in insulin treated diabetics. Lancet, i, 1049.

HARWOOD, R. (1960) Insulin binding antibodies and spontaneous hypoglycaemia. New England Journal of Medicine, 262, 978.
Pickup, J.C., Horne, P.D., Bilous, R.W., Keen, H. \& Alberti, K.G.M.M. (1981) Management of severely brittle diabetes by continuous subcutaneous and intramuscular insulin infusions. British Medical Journal, 282, 347.

PickuP, J.C., KeEn, H., PARSONS, J., Alberti, K.G.M.M. \& Rowe, A.S. (1979) Continuous subcutaneous insulin infusions; improved blood glucose and intermediate metabolite control in diabetics. Lancet, i, 1255.

TAYLOR, S.I., GRUNBERGER, G., MARCUS-SAMUEL, B., UNDERHILL, L.H., Dons, R.F., RYAN, J., RODdan, R.F., RUPE, C.E. \& GORDEN, P. (1982) Hypoglycaemia associated with antibodies to the insulin receptor. New England Journal of Medicine, 307, 1422.

(Accepted 23 December 1982) 